\section{$\underset{\text { hommes }}{\text { \& migrations }}$}

\section{Hommes \& migrations}

Revue française de référence sur les dynamiques

migratoires

1317-1318 | 2017

L'Europe en mouvement

\title{
Sylvie Kandé, Gestuaire
}

Paris, Gallimard, 2016, 112 p., 12,50€.

\section{Mustapha Harzoune}

\section{(2) OpenEdition}

1 Journals

\section{Édition électronique}

URL : http://journals.openedition.org/hommesmigrations/3946

DOI : 10.4000/hommesmigrations.3946

ISSN : 2262-3353

Éditeur

Musée national de l'histoire de l'immigration

\section{Édition imprimée}

Date de publication : 1 avril 2017

Pagination : 200-201

ISBN : 978-2-919040-38-4

ISSN : 1142-852X

Référence électronique

Mustapha Harzoune, «Sylvie Kandé, Gestuaire », Hommes \& migrations [En ligne], 1317-1318| 2017, mis en ligne le 01 avril 2017, consulté le 24 septembre 2020. URL : http://journals.openedition.org/ hommesmigrations/3946; DOI : https://doi.org/10.4000/hommesmigrations.3946 


\section{LIVRES}

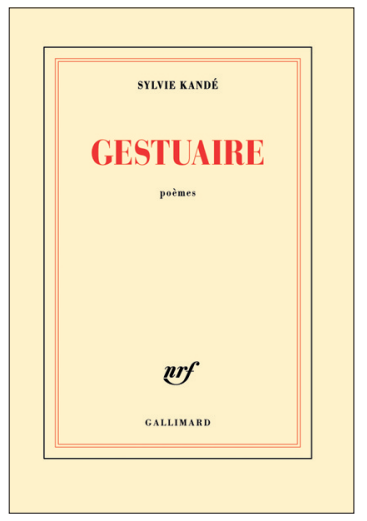

\section{Sylvie Kandé Gestuaire \\ Paris, Gallimard, 2016, 112 p., 12,50€.}

Gestuaire. Pour dire les gestes. Anodins ou intimes. Des gestes comme des miettes, " comme celles qu'au sortir de table / on pousse d'un coup

d'éponge ". Gestes qui trahissent ou révèlent. Gestes de vie ou de mort. Gestes rares, inscrits " dans une fragile éternité ", répétant un commun "rêve de liberté »: « L'obscure histoire de neuf Marrons / qu'on pendit haut et court au tronc d'un cocotier " ou ces "Bouches cousues en prévision des interviews ". II ne faut pas compter sur l'« Encens qui monte au gré des prières / en un vertical mépris de tout ici-bas " pour porter ce rêve, rapporter ces gestes. "Non les gratte-ciel hautains / n'en auront jamais cure / de ces phalènes dorés / au sort soudain. " Comme la pierre n'a que faire de l'amour d'un œuf: "Car elle à l'aise dans sa masse / rien de rien elle ne sent rien / du piètre sacrifice poisseux / qui se joue dessus sa carapace / et son cœur ne serait en être éclaboussé ". Indifférence, mépris pour les faibles et les humbles. Pour eux, " un poème - toujours / sera meilleur conque ». C'est au peintre-Édouard Duval-Carrié ici et son Retable des Neuf Esclaves - et aux poètes qu'échoit "la tâche de conter telle quelle ».

" Un geste et tout s'explique, ou rien ne va plus » écrit Sylvie Kandé, et « c'est le corps qui scelle l'aventure poétique, la main qui scelle une brique dans l'édifice infini du langage ". C'est donc par le corps qu'il faut s'aventurer sur les sentes d'une poésie rare. Exigeante. Luxuriante et touffue. Acrobatique aussi. Souple et dense, elle se risque au funambulisme des mots pour "apprivoiser ce qui ne s'entend ni ne s'écrit ". Les mots! Ils sont exhumés de l'oubli et de l'ignorance. Réinventés, inventés, néologisés, métissés, malaxés, assemblés (sans ponctuation souvent, pour la liberté du souffle), télescopés. Funambulisme des constructions aussi : versifiées ou libres, musicales, ramassées en litotes, en métaphores et autres analogies, visuelles avec la présence ou l'absence de majuscules, les retours à la ligne et les lacunes. Cette poésie ne cultive pas l'azur, "survivre dit-elle jamais ne tient qu'à un fil ». Il faut dire que ce recueil parle de la violence du négrier, du génocidaire (" comment calculez-vous la différence?"), du colon, de la loi, des frontières (" qu'une frontière au lieu de diviser accote ") et, trop souvent contrariées, de ces rêves de liberté des marrons, des migrants (" aux balafres de l'exil / point de médecine »), des "pas comptés » et des "phalènes dorés ». En ne cédant pas à la facilité de la dénonciation, Sylvie Kandé refuse de s'abstraire de la complexité du monde. De la polysémie, et de l'ambiguïté parfois, des gestes (voir "Au temps jadis »). S'y ajoute, espace du dialogisme, la liberté de dire et d'être entendu: " Je me parle beaucoup à moi-même à haute voix je songe / Et s'il vous arrive d'ouir de ces tête-àtête certaines inconvenances / n'allez pas me pendre au cou la pierre du 
mensonge / [...] Mettez ces fredaines au compte de la saison / de la lune ou de l'harmattan / de l'habitude de lire sans bougie / de penser en spirale / et de chanter sans répons. »

Chez cette historienne de formation, spécialiste en littérature (classique, grecque, francophone africaine et caribéenne, afro-américaine) et autres métissages, le passé et le présent vont et viennent, s'éclairent et s'ensemencent. Ainsi, "Coup de chapeau » : "La loi m'atten- dait au tournant. Me figer sur place ferait louche, garder les mains en poche, désinvolte, un rien menaçant. Allez donc à sa rencontre sans trop prendre suée, en calculant l'allure - histoire de montrer dû respect, mesure et dignité, de ne pas éveiller le soupçon. On ne badine pas avec la loi. " Non on ne badine pas avec la loi et du côté d'Aulnay-sous-Bois, parfois, la matraque a remplacé le « fier salacot ». M. H.

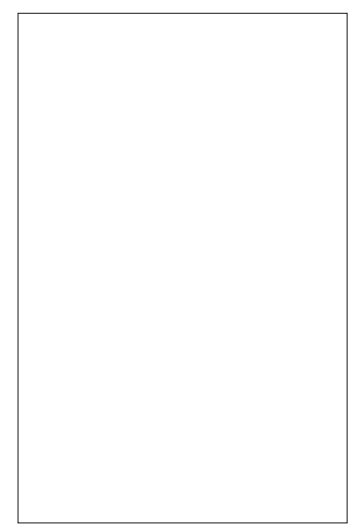

\section{Renaud de Rochebrune, Benjamin Stora} taGuerre d'Algérie vue parles

Algériens. 2. De la bataille d'Alger a l’Indépendance Paris, Denoël, 2016,444 p., 23,50 €.

Voici enfin le second volet decettehistoire de laguerre d'Algérie vue partes Algériens. Guerre d'Algérie et plus encore car, si la première livraison (2011) remontait jusqu'aux heures sombres de ta pénétration coloniale, cette dernière s'ouvre sur la Bataille d'Alger mais ne se referme pas sur l'année charnière, 1962 . Nos deux auteurs furètent encore dans ces premières années de l'Indépendance et au-delà, et listent en guise de conclusion les débats et les enjeux du moment, aussi bien pour les sociétés française et atgérienne qu'en matière de relations entre les deux pays.
Ce second tome confirme les (bonnes) impressions du premier et la nécessité de ce retour sur cette page terrible de thistoire franco-algérienne, pour dégager l'histoire et les citoyens des instrumentalisations. Si d'une manière générate et pour le dire à gros traits, te premier tome rappelait la france à ses responsabilités, à une mise à plat de son historire coloniate - qui ne fut pas ce qu'uncandidat à la présidentielte frappé d'amnésie ou d'ignorance prétend-, ce tivre semble, plus encore que te précé= dent, ptonger dans tes pages noires de ta révolution algérienne:

Bien sûr, il y a les événements et leur ehronotogie, il y a les hommes et les politiques, celte, sinueuse ou plus sûrement pragmatique, du général de Gaulle notamment. Mais ici, comme précédemment, les auteurs pointent tes amnésies, les réécritures de l'histoire, les trous et les mensonges de thistoire officielle - version atgérienne cette fois. Ce qui est montré ici, en de tongs développements, nom plus d̀ partir des caches et autres planques, 